\title{
Predatory publishers and fraudulent conferences: Perspectives and implications for novice researchers
}

\author{
Eric Mercier ${ }^{1,2,3} \cdot$ Pier-Alexandre Tardif ${ }^{1} \cdot$ Marcel Émond $^{1,2,4} \cdot$ Natalie Le Sage $^{1}$
}

Published online: 25 October 2017

(C) The Author(s) 2017. This article is an open access publication.

Shortly after publishing our first article, we (EM, PAT) started receiving daily electronic invitations to submit additional manuscripts to unfamiliar journals and present at questionable conferences. Unfortunately, our experience is not unique. Considering the intense pressure to publish during medical training, limited knowledge of predatory publishing entities, and lack of local institutional policies to guide trainees' responses to these flattering invitations, this trend is especially concerning.

Publishing in medical journals and presenting at health conferences are valued accomplishments across the continuum of medical education. For example, the number of publications is often used as a metric of productivity and postgraduate trainees are expected to possess lengthy bibliographies to compete for positions, promotions, and grants. Specific to novice researchers, their number of research accomplishments is associated with successful applications in competitive residency programs [1]. However, despite the numerous barriers to publishing in well-established journals

Eric Mercier

eric.mercier.2@ulaval.ca

1 Axe Santé des Populations et Pratiques Optimales en Santé, Unité de recherche en Traumatologie-Urgence-Soins Intensifs, Centre de recherche du CHU de Québec, Université Laval, Québec, Canada

2 Centre de recherche sur les soins et les services de première ligne de l'Université Laval, Québec, Canada

3 School of Public Health and Preventive Medicine, Monash University, Melbourne, Victoria, Australia

4 Centre d'excellence sur le vieillissement, Centrede recherche sur les soins de première ligne de l'Université Laval, Québec, Canada (e. g., costs, rejection rates, delays, etc.), trainees are facing an unprecedented pressure to publish.

From our experience, there is a lack of awareness regarding publication ethics and the nature of predatory entities. Personally, we have never been taught about this phenomenon. Furthermore, our discussions with other trainees and their teachers has confirmed our assumption that this is a gap in medical education.

Formal academic institution policies and code of conduct promoting publication in reputable journals over potential predatory publishers are rare [2]. These documents should reflect the institutions' ideal of academic excellence and be endorsed by the research community. Such policies could raise researchers' awareness and discourage unethical behaviours using a structured process to evaluate the use of predatory entities and its potential consequences.

Finally, we are aware of junior colleagues who have published in questionable journals or submitted manuscripts that were never published after having transferred their copyrights. As predatory entities who prioritize profit over scientific value continue to expand, medical trainees will increasingly be targeted.

Concerted actions are required to counteract this phenomenon and protect trainees. For instance, publication ethics should be taught concomitantly with the medical student's introduction to scientific literature and methodology. Additionally, structured educational programs should incorporate training to enhance trainees' ability to appraise journal and publisher credibility (e. g., using guidelines promoted by the Committee of Publication Ethics) [3]. Clinical teachers and researchers should also work together to mentor students in interpreting, producing and presenting research results ethically. Finally, we think development of institutional policies is essential and we intend to participate in the development of one at our institution. 
Acknowledgements The authors would like to thank Lauren Maggio, associate editor, for her help and valuable insights regarding this letter.

Funding Eric Mercier is supported by a grant from the Fonds de Recherche en Santé du Québec (FRQS) for his fellowship (Grant 32058).

Open Access This article is distributed under the terms of the Creative Commons Attribution 4.0 International License (http:// creativecommons.org/licenses/by/4.0/), which permits unrestricted use, distribution, and reproduction in any medium, provided you give appropriate credit to the original author(s) and the source, provide a link to the Creative Commons license, and indicate if changes were made.

\section{References}

1. Stratman EJ, Ness RM. Factors associated with successful matching to dermatology residency programs by reapplicants and other applicants who previously graduated from medical school. Arch Dermatol. 2011;147:196-202.

2. Beall J. Predatory journals: Ban predators from the scientific record. Nature. 2016;534(7607):326.
3. COPE. Principles of transparency and best practice in scholarly publishing. 2015. http://publicationethics.org/resources/guidelines. Accessed May 152017

Eric Mercier is an emergency physician (FRCPC) who is currently a research fellow at the Centre de Recherche du CHU de Québec (Québec, Canada) and the School of Public Health and Preventive Medicine of Monash University (Melbourne, Australia). He holds a Master degree in Clinical Epidemiology (MSc).

Pier-Alexandre Tardif holds a Master in Philosophy of Science (MA) and a Master degree in Epidemiology (MS). His research interests include low-value clinical practices, traumatic brain injuries, trauma systems and registries, and predatory publishing.

Marcel Émond is a clinician-scientist and a Professor at the Département de Médecine Familiale et Médecine d'Urgence de la Faculté de Médecine de l'Université Laval (Québec, Canada). He is the director of the Canadian Emergency Departments Team Initiative (CETI).

Natalie Le Sage is a clinician-scientist and a Professor at the Département de Médecine Familiale et Médecine d'Urgence de la Faculté de Médecine de l'Université Laval (Québec, Canada). She is the director of emergency medicine research at the CHU de Québec. 